\title{
Research Paper \\ Differentiating Biliary Atresia from other Causes of Cholestasis Jaundice in Infants
}

\author{
Bui Thi Kim Oanh*, Nguyen Pham Anh Hoa \\ Vietnam National Children's Hospital, 18/879 La Thanh, Dong Da, Hanoi, Vietnam
}

Received 17 July 2020

Revised 14 August 2020; Accepted 17 August 2020

\begin{abstract}
Background/Purpose: Cholestasis is defined as reduced bile Synthesis or biliary flow. It results of varied causes. Early detection of biliary atresia is to intervene in time and have the best outcome. The aim of this study is to find out the cholestatic etiologies in infants and differences of clinical features, laboratory investigations between biliary atresia and other causes of cholestasis at Vietnam National Children's Hospital.

Methods: In this retrospective study, 305 infants under 12 months of age with cholestasis were studied in Vietnam National Children's Hospital during 1/2017-7/2018. Demographic data, duration of jaundice, signs and symptoms as well as laboratory, imaging, liver biopsy and the causes of cholestasis were recorded, divided into 2 groups BA and Non-BA.

Results: 305 infants (194 boys, 111 girls) with cholestasis and mean age of 83,22 $\pm 72,10$ days were included in the study. The most common causes of cholestasis were idiopathic neonatal hepatitis $(33,8 \%)$, biliary atresia $(25,9 \%)$, cytomegalovirus infection $(21,6 \%)$. In BA group, pale stool (100\%), Hepatomegaly $(98,7 \%)$; increasing less AST, ALT, more GGT level than Non-BA. AUC of GGT is lagest among AST, ALT, GGT and ALP. Find out GGT cutoff > 212,05 UI/1 in diagnosing BA.

Conclusions: Biliary atresia and idiopathic neonatal hepatitis are the most common causes of infantile cholestasis. Pale stool, hepatomegaly and GGT elevation > 212,05 UI/1 are the reliable tests for diagnosing BA.
\end{abstract}

Keywords: Cholestasis, Biliary atresia, GGT level.

* Corresponding author.

E-mail address: oanhbtk@gmail.com

https://doi.org/10.25073/jprp.v4i4.214 


\title{
Phân biệt teo mật bẩm sinh và các căn nguyên khác gây vàng da ứ mật ở trẻ em
}

\author{
Bùi Thị Kim Oanh*, Nguyễn Phạm Anh Hoa \\ Bệnh viện Nhi Trung uoong, 18/879 La Thành, Đống Đa, Hà Nội, Việt Nam \\ Nhận ngày 17 tháng 7 năm 2020 \\ Chỉnh sửa ngày 14 tháng 8 năm 2020; Chấp nhận đăng ngày 17 tháng 8 năm 2020
}

\section{Tóm tắt}

Đặt vấn đề/ Mục tiêu: Vàng da ứ mật (VDUM) là tình trạng vàng da do suy giảm tổng hợp mật hoặc dòng chảy mật, đặc trưng bởi tăng bilirubin trực tiếp. VDUM do nhiều nguyên nhân gây ra, trong đó teo mật bẩm sinh (TMBS) cần được nhận biết, chẩn đoán, can thiệp sớm để có kết quả điều trị tốt nhất. Nghiên cứu này tìm hiểu nguyên nhân gây VDUM ở trẻ nhỏ và đặc điểm lâm sàng, cận lâm sàng phân biệt teo mật bẩm sinh với các nguyên nhân gây VDUM khác.

Phương pháp: Nghiên cứu hồi cứu 305 trẻ dưới 12 tháng tuổi có tình trạng ứ mật tại Bệnh viện Nhi Trung ương từ 1/2017-7/2018. Thu thập đặc điểm dịch tễ, lâm sàng và cận lâm sàng, các nguyên nhân được chia 2 nhóm TMBS và không TMBS.

Kết quả: 305 trẻ (194 trẻ trai, 111 trẻ gái) có tình trạng ứ mật, tuổi nhập viện trung bình là $83,2 \pm 72,1$ ngày. Nguyên nhân chiếm tỷ lệ lớn là teo mật bẩm sinh $(25,9 \%)$, nhiễm cytomegalovirus $(21,6 \%)$, viêm gan sơ sinh vô căn còn chiếm tỷ lệ cao $(33,8 \%)$. Ở nhóm teo mật, phân bạc màu (100\%), gan to $(98,7 \%)$; AST, ALT tăng ít hơn, GGT tăng cao hơn so với nhóm không teo mật. Diện tích dưới đường cong của GGT lớn nhất trong 4 chỉ số $\mathrm{AST}$, ALT, GGT, ALP và tìm thấy điểm cutoff của GGT > 212,05 UI/1 trong chẩn đoán TMBS.

Kết luận: Teo mật bẩm sinh và viêm gan sơ sinh vô căn chiếm tỷ lệ cao gây VDUM. Phân bạc màu, gan to, GGT $>212,05$ là những chỉ điểm giúp phân biệt TMBS với các nguyên nhân khác gây VDUM.

Tù khóa: Vàng da ứ mật, teo mật bẩm sinh, giá trị GGT.

\section{1. Đặt vấn đề}

Vàng da ứ mật (VDUM) là tình trạng vàng da do giảm tổng hợp mật hoặc dòng chảy mật, đặc trưng bởi tình trạng tăng bilirubin trực tiếp máu. Tỷ lệ mắc VDUM ở trẻ em là 1/2500 trẻ sinh sống. VDUM do

"Tác giả liên hệ.

Địa chỉemail: oanhbtk@gmail.com

https://doi.org/10.25073/jprp.v4i4.214 nhiều nguyên nhân gây ra trong đó bệnh lý teo đường mật bẩm sinh (TMBS) là hay gặp nhất [1]. Biểu hiện lâm sàng của VDUM bao gồm vàng da xỉn, biến đổi màu phân, nước tiểu sẫm màu, triệu chứng gan to đi kèm lách to hoặc không, các triệu chứng rối loạn đông máu, xơ gan... Teo mật bẩm sinh là tình trạng tăng sinh xơ tiến triển của đường mật trong và ngoài gan, khởi phát trong 3 tháng đầu đời. Thời điểm phẫu thuật tốt nhất là trước 60 ngày tuổi, giúp phục hồi 
dòng chảy đường mật, cải thiện chức năng gan. Nếu không được can thiệp phẫu thuật sớm, ứ mật tiến triển dẫn tới xơ gan, bệnh gan giai đoạn cuối và tử vong trong vòng 1-2 năm đầu đời. Tuy nhiên, triệu chứng của TMBS không đặc hiệu, dễ nhầm lẫn và chồng lấp với các nguyên nhân gây VDUM khác, chẩn đoán xác định TMBS cần dựa vào chụp đường mật và sinh thiết gan trong mổ. Một nghiên cứu của Sun $\mathrm{S}$. Et al cho thấy trong số 602 bệnh nhân nghi ngờ teo mật trải qua phẫu thuật chỉ có $86 \%$ số ca được khẳng định là TMBS dựa trên kết quả mô bệnh học [2]. Tìm ra dấu hiệu, triệu chứng giúp phát hiện sớm, định hướng chẩn đoán TMBS là thật sự cần thiết để tránh bỏ sót cũng như chỉ định mổ nhầm. Chính vì vậy chúng tôi tiến hành nghiên cứu với mục tiêu "Tìm hiểu các đặc điểm lâm sàng và cận lâm sàng giúp phân biệt teo mật bẩm sinh với các nguyên nhân khác gây VDUM ở trẻ em"

\section{2. Đối tượng và phương pháp nghiên cứu}

Đối tượng nghiên cứu: Lựa chọn các bệnh nhân đủ tiêu chuẩn chẩn đoán VDUM trong thời gian nghiên cứu từ 1/20177/2018 tại bệnh viện Nhi Trung ương

Tiêu chuẩn lựa chọn: Bệnh nhân có tuổi từ $0-12$ tháng, đủ tiêu chuẩn chẩn đoán VDUM.
Tiêu chuẩn loại trừ: Bệnh nhân VDUM kèm theo các tình trạng bệnh phức tạp, bố mẹ trẻ từ chối điều trị.

Phương pháp nghiên cứu: Nghiên cứu hồi cứu một loạt ca bệnh

Cõ̃ mẫu: Chọn mẫu thuận tiện

Biến số và công cụ thu thập thông tin: Thu thập số liệu hồ sơ bệnh án lưu trữ, gồm các biến số thời điểm xuất hiện vàng da, gan to, lách to, phân bạc màu và các chỉ số xét nghiệm. Chia thành 2 nhóm teo mật (có phẫu thuật Kasai và chẩn đoán mô bệnh học) và không teo mật.

Xử lý và phân tích số liệu: Nhập và xử lý số liệu bằng phần SPSS 20.0. Xử lý số liệu theo phương pháp thống kê y học, Chi square test so sánh 2 trung bình, đường cong ROC.

\section{Kết quả nghiên cứu}

- Đặc điểm chung của nhóm nghiên cứu

Thời gian nghiên cứu thu thập được 305 trẻ đủ tiêu chuẩn nghiên cứu, nam chiếm $63,6 \%$, nữ $36,4 \%$; trong nhóm teo mật, trẻ nữ chiếm ưu thế là $51,9 \%$.

Tuổi nhập viện trung bình $83,2 \pm 72,1$ ngày trong đó tuổi nhập viện của nhóm teo mật $71 \pm 28,9$ ngày sớm hơn so với nhóm không teo mật $87,5 \pm 82,8$ ngày.

Trẻ đẻ đủ tháng là chủ yếu chiếm $78,7 \%$, tỷ lệ trẻ đẻ đủ tháng trong nhóm teo mật 94,9\% (Bảng 1).

Bảng 1. Đặc điểm chung của nhóm đối tượng nghiên cứu

\begin{tabular}{|l|l|c|c|c|}
\hline \multicolumn{2}{|c|}{ Chỉ số } & BA & Non-BA & \multirow{2}{*}{$\mathrm{N}(\%)$} \\
\hline \multirow{2}{*}{ Giới } & Nam & $38(48,1)$ & $156(69)$ & \multirow{2}{*}{$<0.001$} \\
\cline { 2 - 5 } & Nũ & $41(51,9)$ & $70(31)$ & \\
\hline \multirow{2}{*}{ Đẻ thường } & Đẻ thường & $55(69,6)$ & $162(71,7)$ & \multirow{2}{*}{$>0.05$} \\
\cline { 2 - 4 } & Đẻ mồ & $24(30,4)$ & $64(28,3)$ & \\
\hline
\end{tabular}




\begin{tabular}{|c|c|c|c|c|}
\hline \multirow{4}{*}{ Tuổi thai (tuần) } & TB tuổi thai & $38.87 \pm 0.87$ & $37.84 \pm 0.28$ & $<0.001$ \\
\hline & <38 tuần & $4(5,1)$ & $61(27)$ & \multirow{3}{*}{$<0.001$} \\
\hline & 38-42 tuần & $75(94,9)$ & $165(73)$ & \\
\hline & >42 tuần & $0(0)$ & $0(0)$ & \\
\hline \multirow{3}{*}{$\begin{array}{l}\text { Cân nặng khi } \\
\text { sinh(gram) }\end{array}$} & $\begin{array}{l}\text { TB Cân nặng } \\
\text { lúc sinh }\end{array}$ & $\begin{array}{c}3088.61 \pm \\
384.30\end{array}$ & $\begin{array}{c}2744.69 \pm \\
688.15\end{array}$ & $<0.001$ \\
\hline & $<2500 \mathrm{gr}$ & $3(3,8)$ & $63(27,9)$ & \multirow{2}{*}{$<0.001$} \\
\hline & $>=2500 \mathrm{gr}$ & $76(96,2)$ & $163(72,1)$ & \\
\hline Tuổi nhập viện (ngày) & Trung bình & $70.95 \pm 27.87$ & $87.51 \pm 82.82$ & $<0.05$ \\
\hline
\end{tabular}

- Các nguyên nhân gây vàng da ứ mật Teo mật bẩm sinh và viêm gan $\mathrm{CMV}$ (Cytomegalo virus) là 2 nguyên nhân chiếm tỷ lệ cao gây VDUM với tỷ lệ $25,9 \%$ và 21,6\%. Nhóm VDUM chưa rõ nguyên nhân (viêm gan sơ sinh vô căn) còn chiếm tỷ lệ cao 33,8\%. Một số nguyên nhân ít gặp hơn

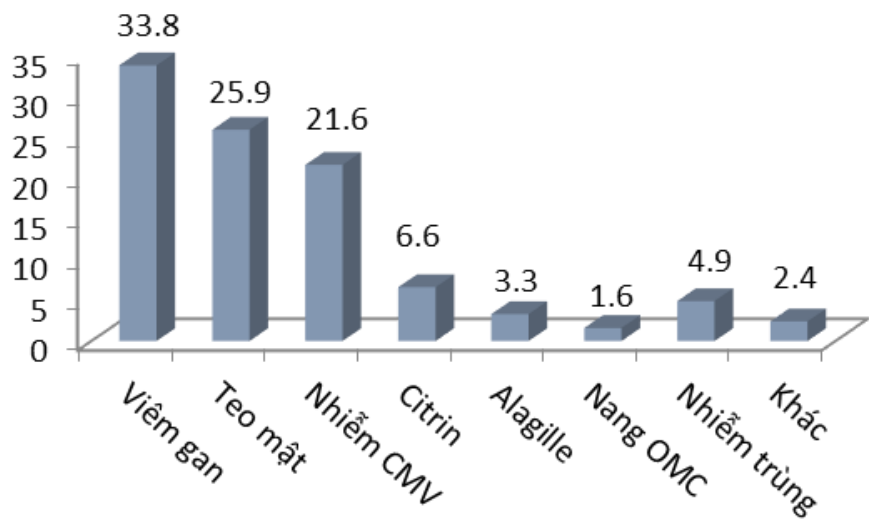

Biểu đồ1. Nguyên nhân gây vàng da ứ mật.

Bảng 2. Đặc điểm lâm sàng giữa 2 nhóm teo mật và không teo mật

\begin{tabular}{|l|c|c|c|c|}
\hline \multicolumn{2}{|c|}{ Chỉ số } & $\begin{array}{c}\text { Teo mật } \\
\mathrm{N}(\%)\end{array}$ & $\begin{array}{c}\text { Không teo mật } \\
\mathrm{N}(\%)\end{array}$ & \multirow{2}{*}{$\mathrm{p}$} \\
\hline \multirow{2}{*}{$\begin{array}{l}\text { Vàng da lúc } \\
\text { 1tuần }\end{array}$} & Có & $70(92,1)$ & $152(68,8)$ & \multirow{2}{*}{$<0.001$} \\
\hline \multirow{3}{*}{ Mức độ vàng } & Không & $6(7,9)$ & $69(31,2)$ & \\
\cline { 2 - 4 } & Nhẹ & $8(10,3)$ & $54(24,2)$ & \multirow{2}{*}{$<0.05$} \\
\cline { 2 - 4 } & Vừa & $64(82,1)$ & $151(67,7)$ & \multirow{2}{*}{$<0.001$} \\
\cline { 2 - 4 } Màu phân & Nặng & $6(7,7)$ & $18(8,1)$ & \\
\cline { 2 - 4 } & Bạc màu & $79(100)$ & $76(33,6)$ & \\
\cline { 2 - 4 } & Bình thường & $0(0)$ & $150(66,4)$ & \\
\hline
\end{tabular}




\begin{tabular}{|c|c|c|c|c|}
\hline \multirow{3}{*}{ Phân bạc màu } & Bạc hoàn toàn & $56(71,8)$ & $9(11,8)$ & \multirow{3}{*}{$<0.001$} \\
\hline & Vàng nhạt & $22(28,2)$ & $62(82,9)$ & \\
\hline & Bạc từng đợt & $0(0)$ & $4(5,3)$ & \\
\hline \multirow{2}{*}{ Gan to } & Có & $78(98,7)$ & $195(86,3)$ & \multirow{2}{*}{$<0.001$} \\
\hline & Không & $1(1,3)$ & $31(13,7)$ & \\
\hline \multirow{3}{*}{ Mật độ gan } & Mềm & $40(50,6)$ & $158(79,8)$ & \multirow{3}{*}{$<0.001$} \\
\hline & Chắc & $38(48,1)$ & $37(18,7)$ & \\
\hline & Cứng & $1(1,3)$ & $3(1,5)$ & \\
\hline \multirow{4}{*}{ Kích thước gan } & Trung bình & $3.15 \pm 0.66$ & $2.78 \pm 0.81$ & $<0.001$ \\
\hline & $<2 \mathrm{~cm}$ & $1(1,3)$ & $7(3,5)$ & \multirow{3}{*}{$>0.05$} \\
\hline & $2-<4 \mathrm{~cm}$ & $57(72,2)$ & $159(80,3)$ & \\
\hline & $\geq 4 \mathrm{~cm}$ & $21(26,6)$ & $32(16,2)$ & \\
\hline \multirow{2}{*}{ Lách to } & Có & $64(81)$ & $108(48,2)$ & \multirow{2}{*}{$<0.001$} \\
\hline & Không & $15(19)$ & $117(51,8)$ & \\
\hline
\end{tabular}

Vàng da, phân bạc màu, gan to, lách to là các triệu chứng hay gặp nhất trong đó vàng da gặp ở tất cả bệnh nhân $100 \%$, gan to gặp 86,8\%, phân bạc màu gặp 50,8\%. Có sự khác biệt có ý nghĩa thống kê giữa thời điểm xuất hiện vàng da, triệu chứng phân bạc màu, gan to và lách to giữa nhóm teo mật và các nguyên nhân gây vàng da ứ mật khác.

Đặc điểm cận lâm sàng

Bảng 3. Xét nghiệm cận lâm sàng giữa 2 nhóm teo mật và không teo mật

\begin{tabular}{|c|c|c|c|c|}
\hline \multicolumn{2}{|c|}{ Chỉ số } & $\begin{array}{l}\text { Teo mật } \\
(\mathrm{n}=79)\end{array}$ & $\begin{array}{l}\text { Không teo mật } \\
(\mathrm{n}=226)\end{array}$ & $\mathrm{p}$ \\
\hline \multicolumn{2}{|c|}{$\mathrm{AST}($ mean $\pm \mathrm{SD})$} & 256,1 & 367,2 & $<0,001$ \\
\hline \multirow{3}{*}{$\begin{array}{l}\text { AST } \\
\text { (UI/l) }\end{array}$} & $<80$ & $1(1,3)$ & $14(6,2)$ & \multirow{3}{*}{$>0,05$} \\
\hline & $80-200$ & $35(44,3)$ & $73(32,3)$ & \\
\hline & $>200$ & $43(54,4)$ & $139(61,5)$ & \\
\hline \multicolumn{2}{|c|}{ ALT (mean) } & 150,3 & 201,8 & $<0,001$ \\
\hline \multirow{3}{*}{$\begin{array}{l}\text { ALT } \\
(\mathrm{UI} / \mathrm{l})\end{array}$} & $<80$ & $24(30,4)$ & $57(25,2)$ & \multirow{3}{*}{$>0,05$} \\
\hline & $80-200$ & $34(43)$ & $86(38,1)$ & \\
\hline & $>200$ & $21(26,6)$ & $83(36,7)$ & \\
\hline \multicolumn{2}{|c|}{ GGT (mean) } & 566 & 212,5 & $<0,001$ \\
\hline \multirow{3}{*}{$\begin{array}{l}\text { GGT } \\
\text { (UI/l) }\end{array}$} & $<100$ & $1(1,3)$ & $70(31)$ & \multirow{3}{*}{$<0,001$} \\
\hline & $100-200$ & $10(12,7)$ & $85(37,6)$ & \\
\hline & $>200$ & $68(86)$ & $71(31,4)$ & \\
\hline \multicolumn{2}{|c|}{ ALP (mean) (UI/l) } & 615,4 & 703.1 & $<0,05$ \\
\hline
\end{tabular}

Có sự khác biệt có ý nghĩa thống kê của mức tăng transaminase giữa nhóm teo mật và không teo mật, trong đó $\mathrm{AST}$, ALT trung bình của nhóm bệnh nhân teo mật bẩm sinh tăng ít hơn so với nhóm không teo mật. GGT trung bình của các bệnh nhân trong nhóm teo mật tăng cao đáng kể so với nhóm không teo mật $\mathrm{p}<0,05$

- Giá trị của các enzym trong chẩn đoán teo mật bấm sinh

Chỉ số GGT chẩn đoán TMBS có độ chính xác cao $84,2 \%$, độ nhạy và độ đặc 
hiệu $84,8 \%$ và $70,4 \% ; 17,3 \%$. Diện tích dưới đường cong của GGT lớn nhất trong 4 chỉ số AST, ALT, GGT, ALP và tìm thấy điểm cutoff của GGT là $>212,05 \mathrm{UI} / 1$ trong chẩn đoán TMBS.

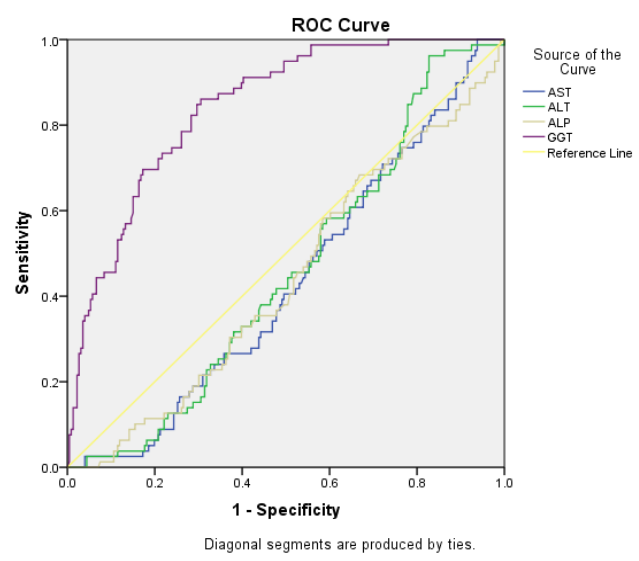

Biểu đồ 2. Đường cong ROC với diện tích dưới đường cong (AUC) của một số enzyme của gan.

\section{Bàn luận}

Theo nhiều nghiên cứu trước đây, teo mật bẩm sinh và viêm gan sơ sinh là 2 căn nguyên hay gặp nhất $[1,3,4]$. Kết quả nghiên cứu của chúng tôi cũng tương tự với viêm gan sơ sinh $33,8 \%$, teo mật bẩm sinh 25,9\%. Một nghiên cứu ở Sydney, tiến hành hồi cứu trên 205 trẻ dưới 6 tháng tuổi, tỷ lệ viêm gan sơ sinh thấp hơn $(25 \%)$ của chúng tôi, nhưng đứng thứ hai là nhóm bệnh rối loạn chuyển hóa và di truyền (23) [5]. Thiếu hụt citrin $(6,6 \%)$ là căn nguyên duy nhất chúng tôi đã xác định được gen gây bệnh. Một số bệnh nhân nghi ngờ rối loạn chuyển hóa biểu hiện suy gan nặng, hạ đường huyết, vàng da tăng dai dẳng, tăng lactac máu hoặc nhóm VDUM có GGT thấp hoặc bình thường, chúng tôi vẫn chưa xác định được nguyên nhân nên được xếp vào nhóm viêm gan sơ sinh vô căn khiến tỷ lệ nhóm này còn cao.
Nhiễm CMV cũng là một nguyên nhân đứng hàng thứ 3 trong nghiên cứu của chúng tôi $(21,6 \%)$, tương tự như nghiên cứu của Phạm Công Luận $(19,1 \%)$ [3], cao hơn nhiều so với nghiên cứu của Lee $(9 \%)$ [1] và Stomon $(1,6 \%)$ [5]. Điều đó cho thây tỷ lệ nhiễm $\mathrm{CMV}$ ở Việt Nam còn rất phổ biến. CMV cũng là một căn nguyên đồng nhiễm với nhiều căn nguyên khác, đặc biệt là nhóm teo mật bẩm sinh.

Việc cố gắng tìm ra các đặc điểm lâm sàng và cận lâm sàng để phân biệt teo mật với các nguyên nhân gây vàng da ứ mật khác đã được tiến hành trong suốt 50 năm qua. Một nghiên cứu lớn tiến hành trên 800 trẻ bú mẹ ở 5 vùng khác nhau Boston, Toronto, London, Houston và Bicetre đã cho thấy có sự khác biệt trên lâm sàng khi so sánh teo mật bẩm sinh với các nguyên nhân gây vàng da ứ mật khác [6]. Trẻ teo mật thường có phân bạc màu, ít bị suy dinh dưỡng và tăng cao các chỉ điểm hóa sinh do tổn thương ống mật và các vi quản mật. Nhiều nghiên cứu gần đây đã bổ xung thêm các đặc điểm chẩn đoán hình ảnh và mô bệnh học để phân biệt [7].

Vàng da ứ mật do nhiều nguyên nhân gây ra, sự hiểu biết về cơ chế bệnh sinh còn chưa rõ ràng, các triệu chứng không đặc hiệu. Chẩn đoán teo mật bẩm sinh không được phép chậm trễ hoặc trì hoãn vì tuổi phẫu thuật là một trong những yếu tố quyết định tiên lượng cuộc mổ. Tuy nhiên không có đặc điểm lâm sàng, cận lâm sàng đơn lẻ nào là đủ mạnh có độ đặc hiệu và độ nhạy cao giúp phân biệt teo mật bẩm sinh với các nhóm vàng da ứ mật khác [1].

Phân bạc màu là triệu chứng rất có giá trị hướng tới teo mật bẩm sinh. Phân bạc màu được coi là có ý nghĩa trong chẩn đoán sớm teo mật khi xuất hiện ngay sau khi đẻ và duy trì sự bạc màu liên tục trong suốt thời gian theo dõi. Trong nghiên cứu này chúng tôi ghi nhận 100\% bệnh nhân teo mật 
có biểu hiện phân bạc màu ở mức độ từ bạc hoàn toàn đến vàng nhạt. Phương pháp tiếp cận chẩn đoán sớm, đơn giản và chi phí thấp, có thể sử dụng để hướng dẫn các bà mẹ chú ý triệu chứng màu phân bạc là sử dụng thẻ màu phân tại các nhà hộ sinh, trạm y tế kết hợp với theo dõi sát các biểu hiện lâm sàng, cận lâm sàng khác tại cơ sở y tế có thể giúp hạn chế chẩn đoán muộn teo mật bẩm sinh.

Đã có rất nhiều nghiên cứu tìm hiểu về giá trị của GGT trong chẩn đoán phân biệt teo mật bẩm sinh với các nguyên nhân gây vàng da ứ mật khác. Các nghiên cứu đều cho thấy GGT tăng cao trong teo mật bẩm sinh và tìm ra điểm cutoff giúp hướng đến teo mật bẩm sinh trên lâm sàng. Theo nghiên cứu của Wright và Christie, GGT> 300 U/1 gợi ý tình trạng ứ mật ngoài gan, nghiên cứu của Chen và cộng sự tìm thấy điểm cutoff là $303 \mathrm{U} / 1$ vơi độ nhạy là $82,8 \%$, độ đặc hiệu $81,6 \%$, độ chính xác là $82,7 \%$ $[8,9]$. Kết quả nghiên cứu của chúng tôi cũng tìm thấy điểm cutoff GGT $>212.05 \mathrm{U} / 1$ với độ nhạy $84,8 \%$, độ đặc hiệu $70,4 \%$ và độ chính xác là $84,2 \%$ trong chẩn đoán teo mật bẩm sinh.

\section{Kết luận}

Có nhiều nguyên nhân gây VDUM ở trẻ em. Teo mật bẩm sinh không chỉ cần được chú ý phát hiện, chẩn đoán sớm mà còn đòi hỏi chặt chẽ về chỉ định phẫu thuật. Phân bạc màu xuất hiện sớm và liên tục là triệu chứng lâm sàng dễ nhận biết song có giá trị chẩn đoán cao. Chỉ số GGT với điểm cut off $>212.05 \mathrm{U} / 1$ có độ nhạy $84,8 \%$, độ đặc hiệu $70,4 \%$ và độ chính xác $84,2 \%$, là chỉ số có giá trị trong chẩn đoán phân biệt teo mật bẩm sinh và các nguyên nhân gây VDUM khác.

\section{Tài liệu tham khảo}

[1] Lee WS, Chai PF. Clinical features differentiating biliary atresia from other causes of neonatal cholestasis. Ann Acad Med Singapore 2010;39(8):648-654.

[2] Sun S, Chen G, Zheng S et al. Analysis of clinical parameters that contribute to the misdiagnosis of biliary atresia. J Pediatr Surg 2013;48(7):1490-1494. https://doi.org/10.101 6/j.jpedsurg.2013.02.034

[3] Luan PC, An PL, Phong NH et al. Characteristics of cholestatic jaundice at the gastroenterology department of Children's Hospital No.2. Journal of Medicine in Ho Chi Minh City 2014;18(1):402-407. (in Vietnamese)

[4] Shahraki T, Miri-Aliabad G, Shahraki M. Frequency of Different Causes of Infant Cholestasis in a Tertiary Referral Center in South-East Iran. Iranian Journal of Pediatrics 2018;28(5):e65409. https://doi.o rg/10.5812/ijp.65409

[5] Stormon MO, Dorney SFA, Kamath KR et al. The changing pattern of diagnosis of infantile cholesta sis. J Paediatr Child Health 2001;37(1):47-50. https://doi.org/10.1046/j.1 440-1754.2001.00613.x

[6] Ferry GD, Selby ML, Udall J et al. Guide to early diagnosis of biliary obstruction in infancy. Review of 143 cases. Clin Pediatr (Phila) 1985;24(6):305-311. https://doi.org/ 10.1177/000992288502400601

[7] Poddar U, Thapa BR, Das A et al. Neonatal cholestasis: differentiation of biliary atresia from neonatal hepatitis in a developing country. Acta Paediatr 2009;98(8):12601264.

[8] Liu CS, Chin TW, Wei CF. Value of gammaglutamyl transpeptidase for early diagnosis of biliary atresia. Zhonghua Yi Xue Za Zhi (Taipei) 1998;61(12):716-720.

[9] Wright K, Christie DL. Use of gammaglutamyl transpeptidase in the diagnosis of biliary atresia. Am J Dis Child 1981;135(2):134-136. 